\title{
Wintertime aerosol dominated by solid fuel burning emissions across Ireland: insight into the spatial and chemical variation of submicron aerosol
}

Chunshui Lin ${ }^{1,2,3}$, Darius Ceburnis ${ }^{1}$, Ru-Jin Huang ${ }^{1,2,3^{*}}$, Wei Xu ${ }^{1,2}$, Teresa Spohn ${ }^{1}$, Damien Martin ${ }^{1}$, Paul Buckley $^{4}$, John Wenger ${ }^{4}$, Stig Hellebust ${ }^{4}$, Matteo Rinaldi ${ }^{5}$, Maria Cristina Facchini ${ }^{5}$, Colin O’Dowd ${ }^{*}$, and Jurgita Ovadnevaite ${ }^{1}$

${ }^{1}$ School of Physics, Ryan Institute's Centre for Climate and \& Pollution Studies, and Marine Renewable Energy Ireland, National University of Ireland Galway. University Road, Galway. H91 CF50, Ireland

${ }^{2}$ State Key Laboratory of Loess and Quaternary Geology and Key Laboratory of Aerosol Chemistry and Physics, Chinese Academy of Sciences, 710061, Xi'an, China

${ }^{3}$ Center for Excellence in Quaternary Science and Global Change, Institute of Earth Environment, Chinese Academy of Sciences, Xi'an 710061, China

${ }^{4}$ School of Chemistry and Environmental Research Institute, University College Cork, Cork, Ireland

${ }^{5}$ Istituto di Scienze dell'Atmosfera e del Clima, Consiglio Nazionale delle Ricerche, 40129 Bologna, Italy

Correspondence to: Ru-Jin Huang (rujin.huang@ieecas.cn) and Colin O’Dowd (colin.odowd@nuigalway.ie)

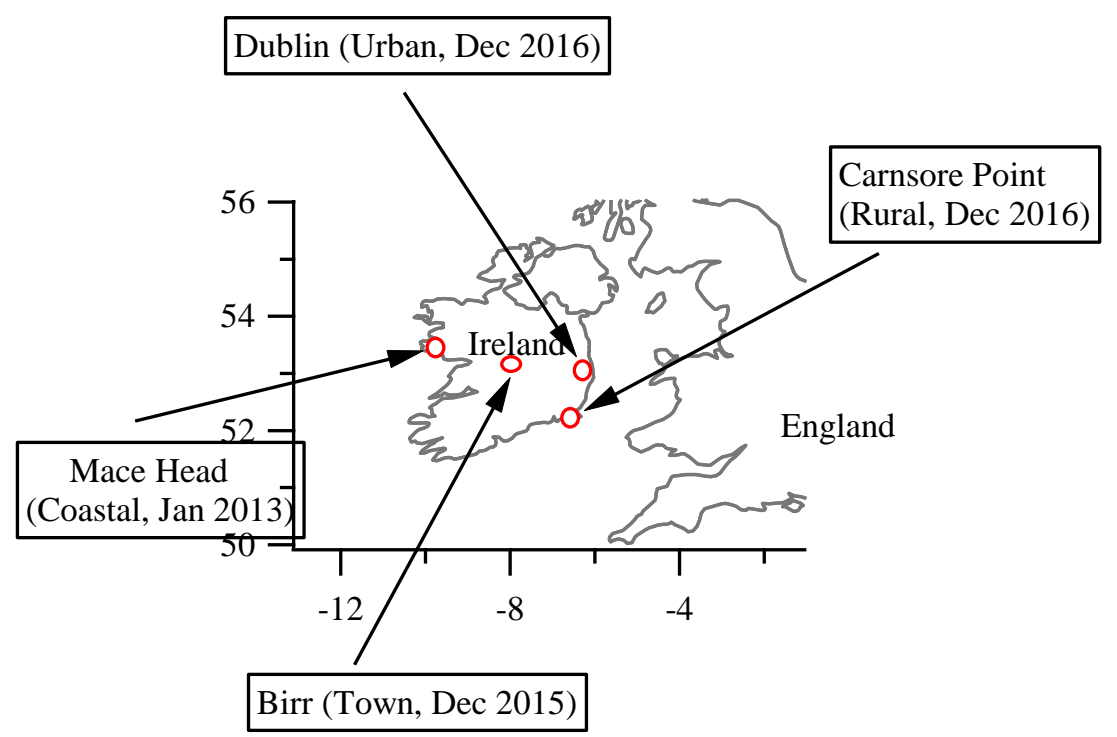

Figure S1. The location of the four measurement sites in Ireland: an urban background site in Dublin; a site in the midland town of Birr; a rural site at Carnsore Point on the east coast and a coastal site at Mace Head on the west coast. The $\mathrm{x}$-axis is the latitude and the $\mathrm{y}$-axis is the longitude. The measurements at the Dublin site and Carnsore Point were conducted simultaneously in December 2016. The measurement at the Birr site was conducted in December 2015 and was in January 2013 for Mace Head. 

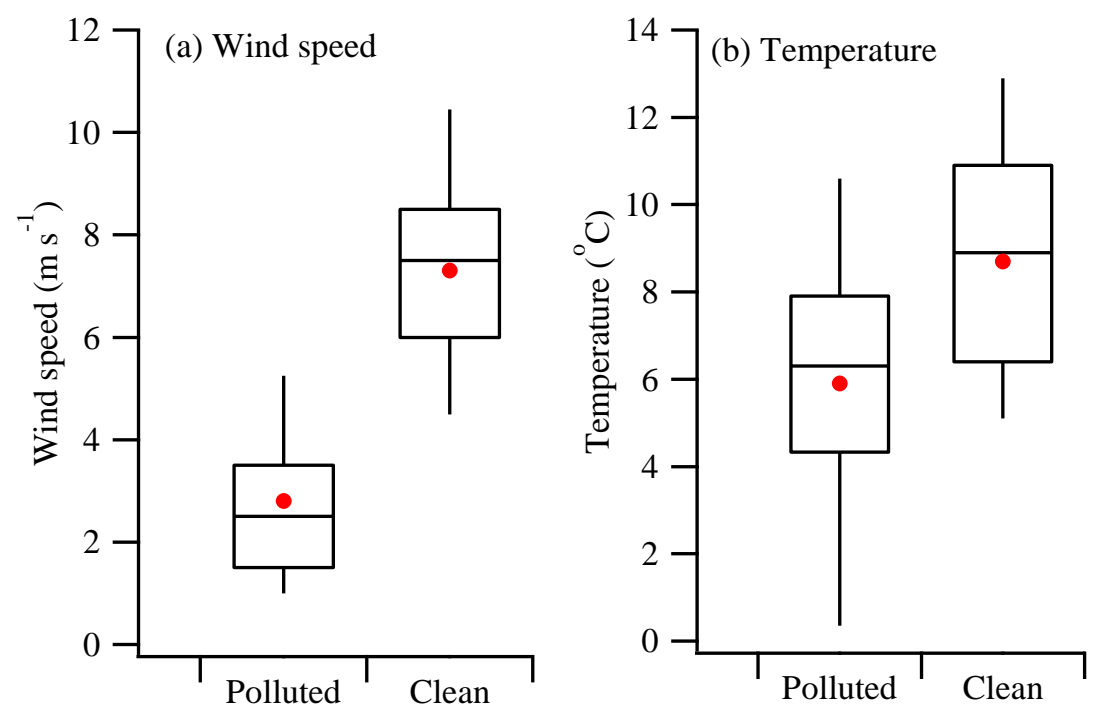

Figure S2. Wind speed (a) and temperature (b) during polluted and clean periods in Dublin December 2016. The boxes represent the 25 th percentile (lower edge), median (solid line), mean (cube mark), and 75 th percentile (higher edge). The whiskers represent the 5 th and $95^{\text {th }}$ percentiles.
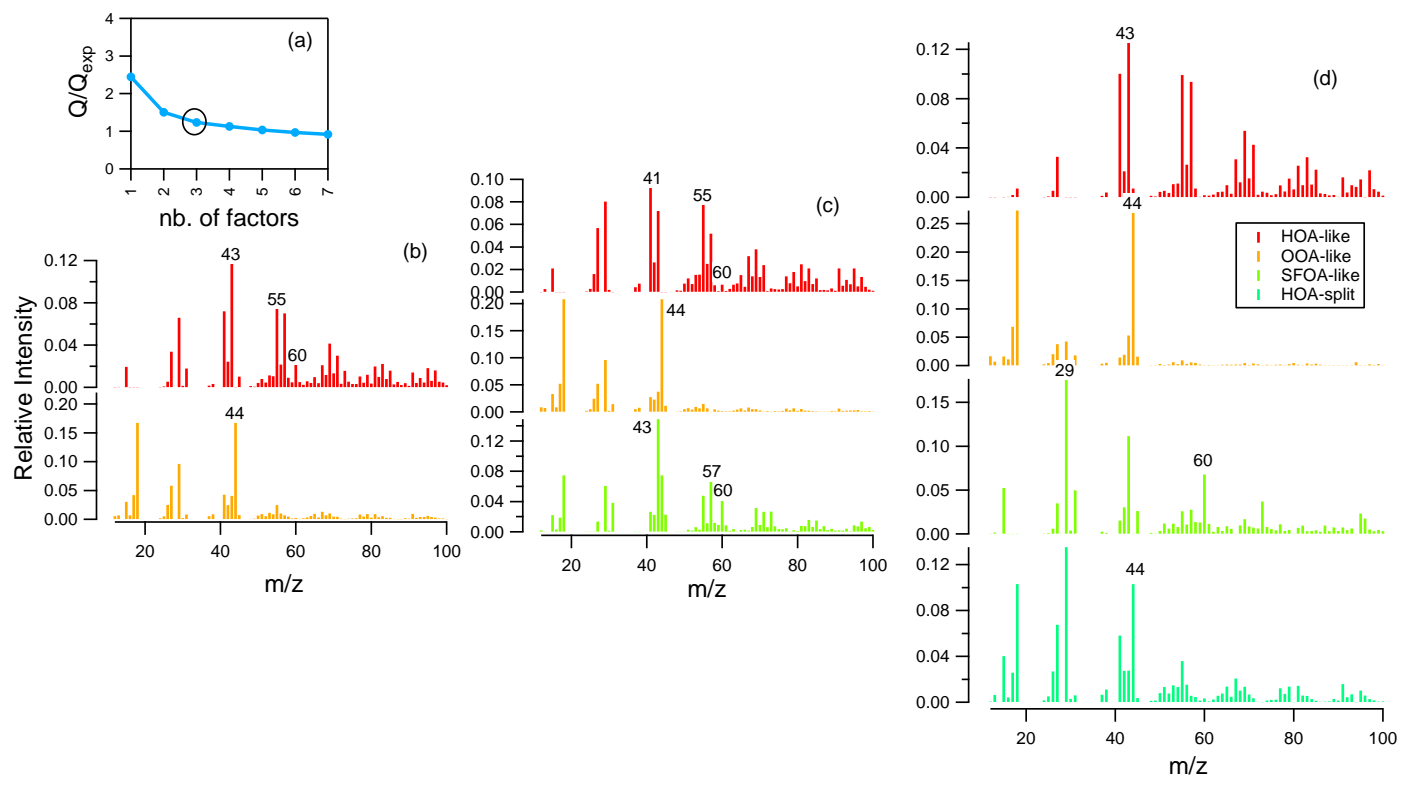

Figure S3. Q/Qexp as a function of number (nb.) of factors (a). Free PMF with 2-4 factor solutions (b-d). There was a slight drop in the Q/Qexp value from 2 to 3 factors, and Q/Qexp was 1.2 at the 3 -factor solution. However, no strong change in $\mathrm{Q} / \mathrm{Q} \exp$ was observed by further increasing the number of factors. The 4-factor solutions led to the splitting of factors as indicated by a good time series correlation between Factor 1 and Factor 4 ( $\mathrm{R}=0.88$ ). 


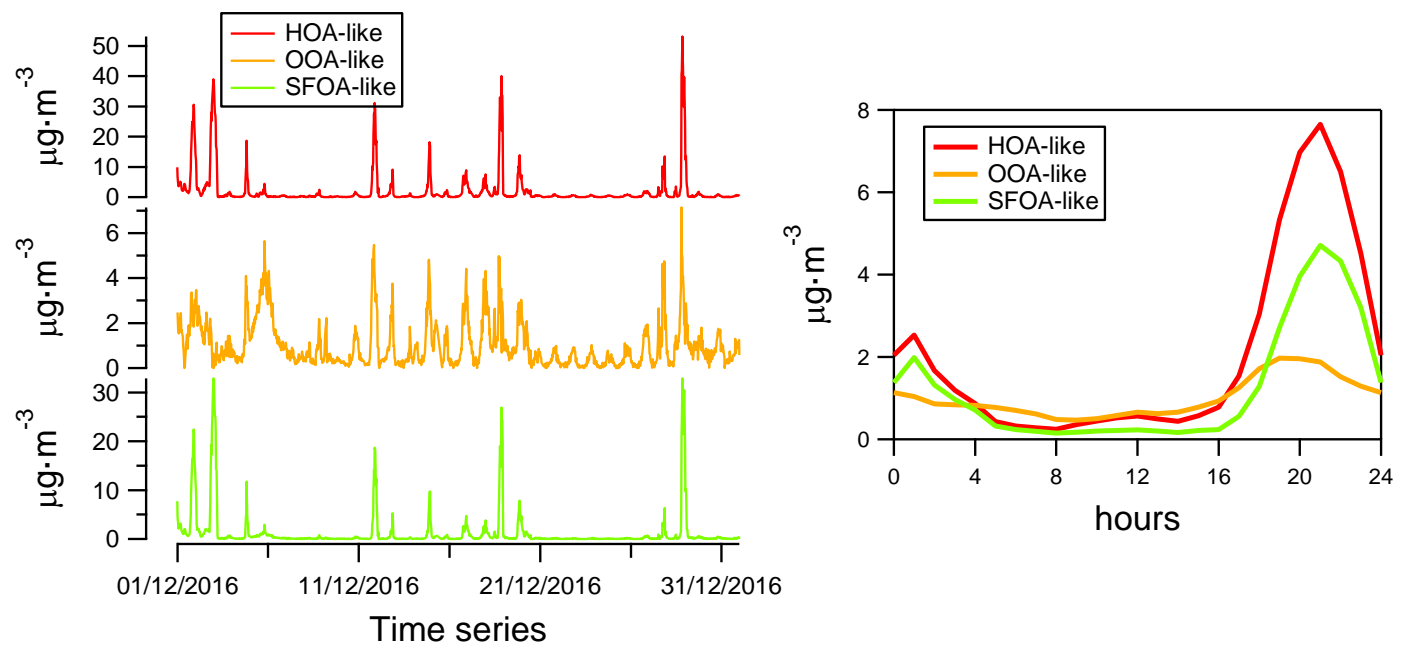

Figure S4. The time series (left) and diurnal pattern (right) of the free PMF 3-factor solution.

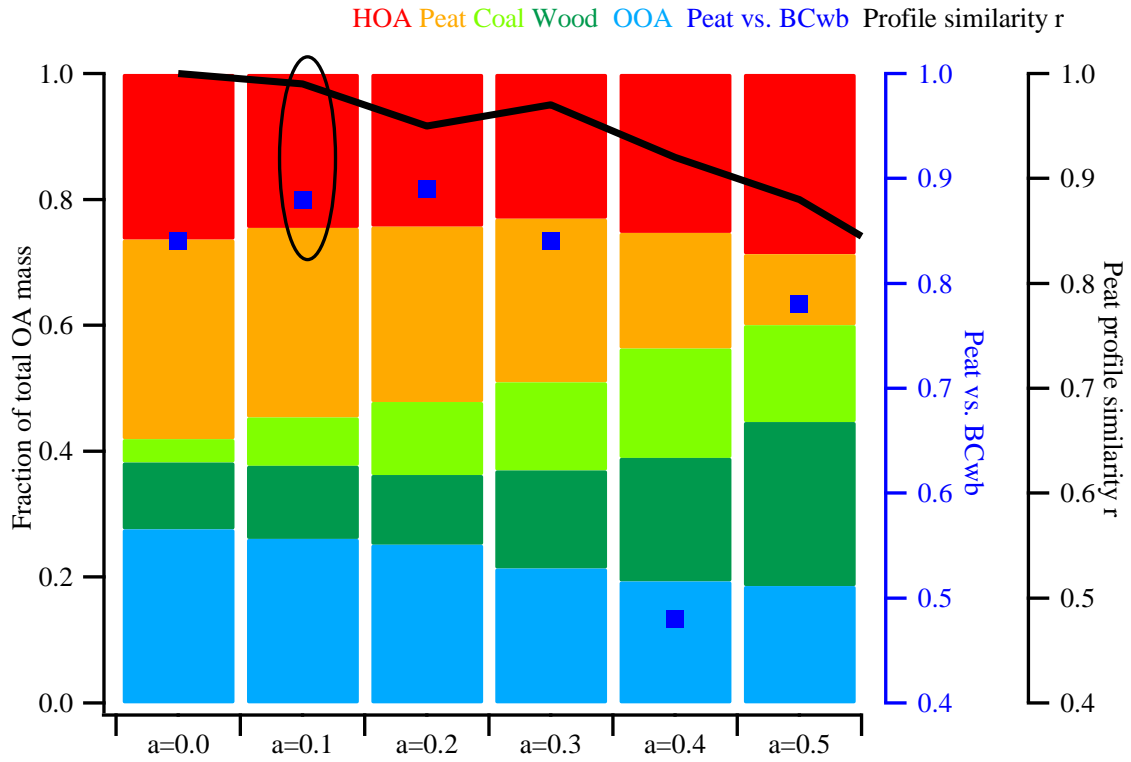

Figure S5. Relative fraction of the resolved factors (left axis), as well as the time series correlation coefficient $\mathrm{r}$ of peat versus BBwb and profile similarity between the resolved factor and reference profile (right axis) as a function of $a$ value. The best $a$ value approach is highlighted by a black circle. 


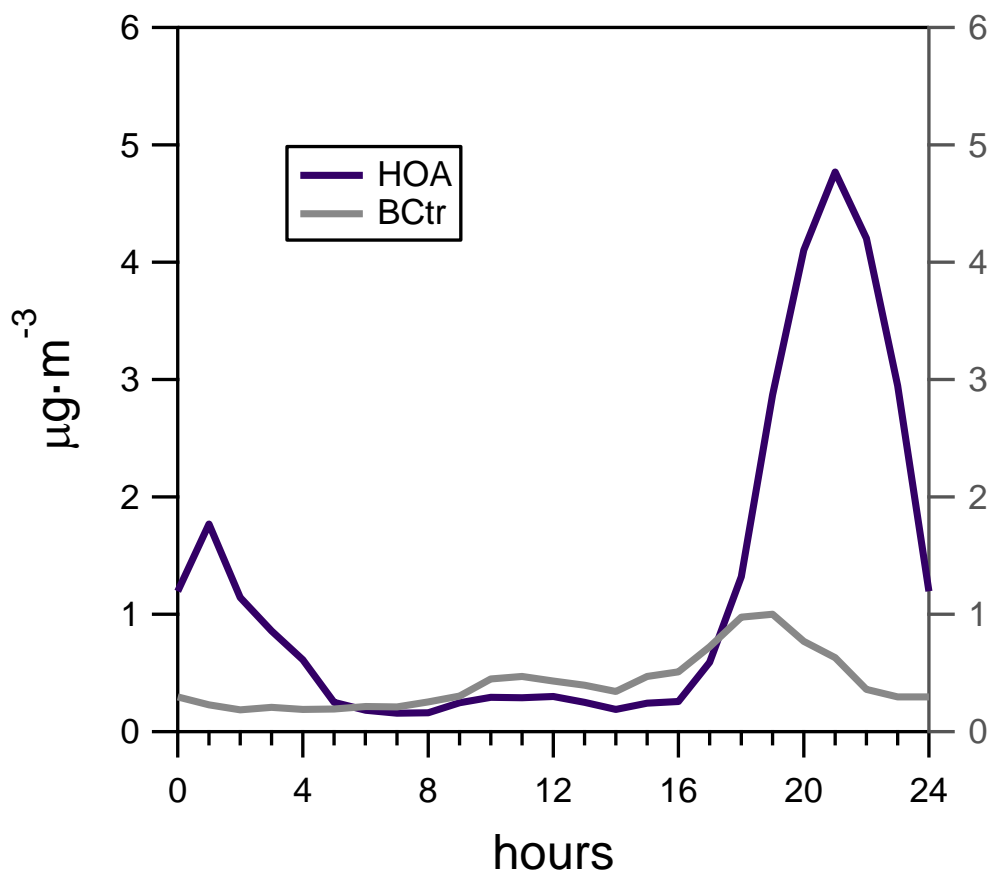

Figure S6. The diurnal pattern of HOA and BCtr in Dublin over the entire period in December 2016. 
(a) Dublin

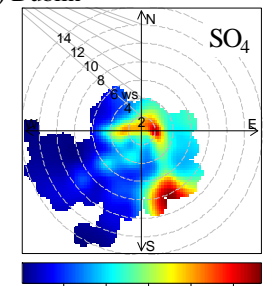

$\begin{array}{lllll}0.2 & 0.4 & 0.6 & 0.8 & 1\end{array}$

(b) Carnsore point

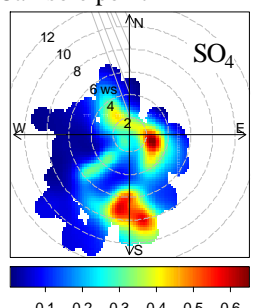

$\begin{array}{lllllll}0.1 & 0.2 & 0.3 & 0.4 & 0.5 & 0.6\end{array}$ (c) Birr

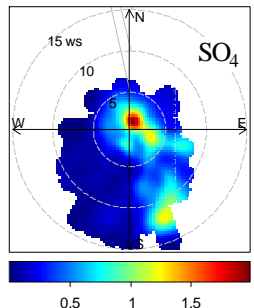

(d) Mace Head

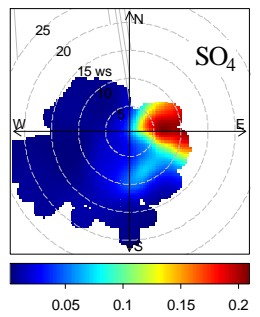

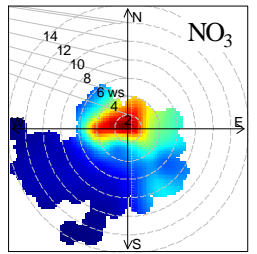

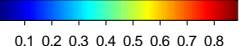
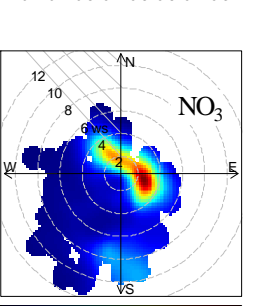

$02040608+1214101$

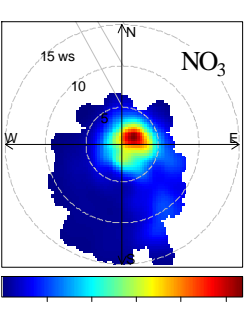

$\begin{array}{lllll}0.2 & 0.4 & 0.6 & 0.8 & 1\end{array}$

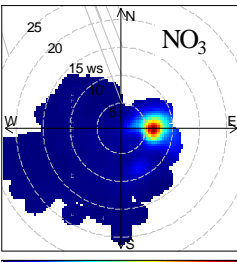

0.10 .20 .30 .40 .50 .60 .70 .80 .9

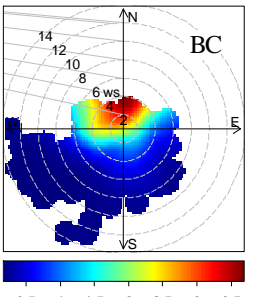

$\begin{array}{lllllll}0.5 & 1 & 1.5 & 2 & 2.5 & 3 & 3.5\end{array}$

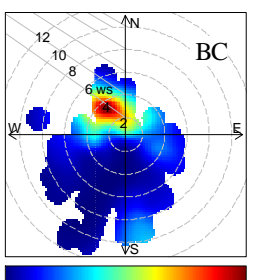

$\begin{array}{lllllll}0.2 & 0.4 & 0.6 & 0.8 & 1 & 12\end{array}$
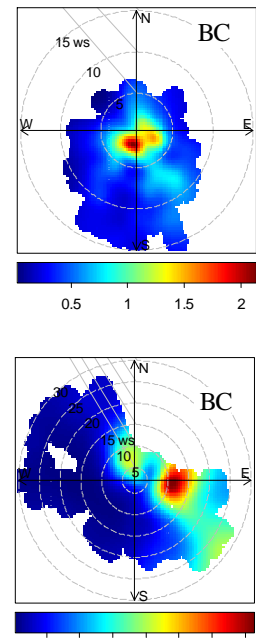

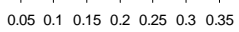
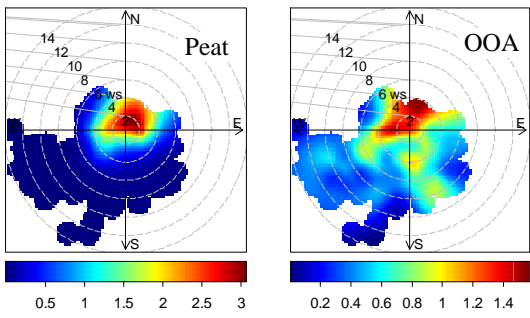

$\begin{array}{lllllll}0.4 & 0.6 & 0.8 & 1 & 1.2 & 1.4\end{array}$

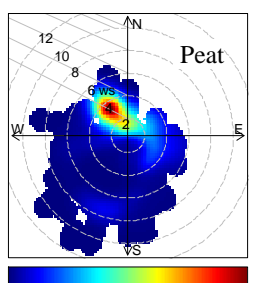

$\begin{array}{llllll}0.1 & 0.2 & 0.3 & 0.4 & 0.5 & 0.6\end{array}$
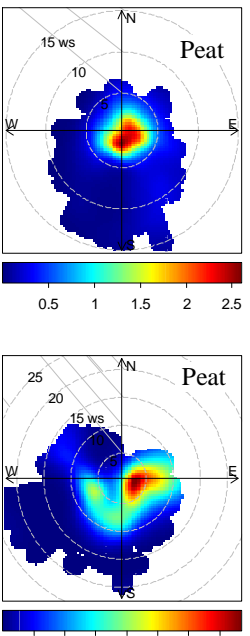

0.010 .020 .030 .040 .050 .060 .07

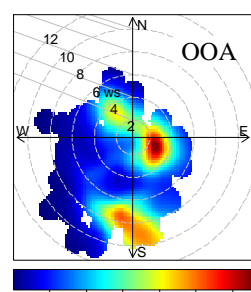

$\begin{array}{llllll}0.2 & 0.4 & 0.6 & 0.8 & 1 & 1.2\end{array}$
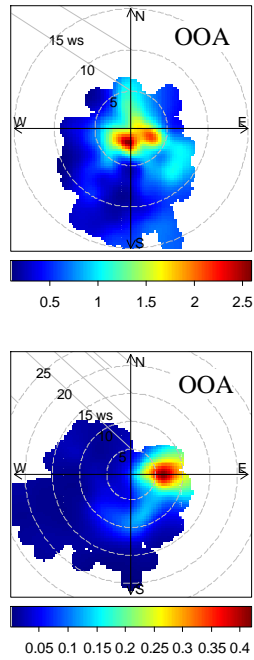

Figure S7. Wind rose of sulfate $\left(\mathrm{SO}_{4}\right)$, Nitrate $\left(\mathrm{NO}_{3}\right)$, black carbon $(\mathrm{BC})$, Peat, and oxygenated organic aerosol (OOA) factor in (a) Dublin; (b) Carnsore Point; (c) Birr; and (d) Mace Head. The plots are color-coded based on concentration of each species in $\mu \mathrm{g} \mathrm{m}^{-3}$. Wind rose plots were generated with OpenAir software in $\mathrm{R}$ (Carslaw and Ropkins, 2012). 

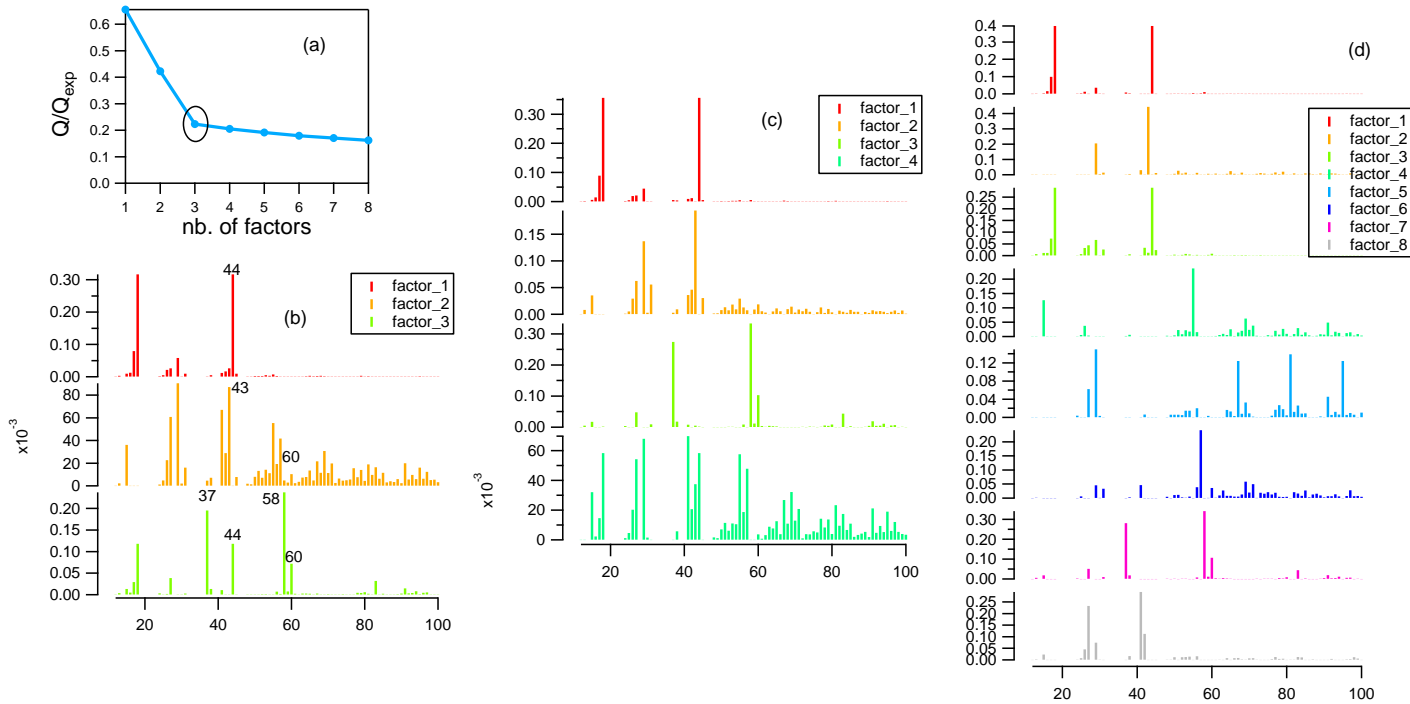

Figure S8. Q/Qexp as a function of number (nb.) of factors (a); free PMF with 3-4 factor solutions (b-c); and 8factor solution (d). There was a large drop in the Q/Qexp value from 2 to 3 factors, and Q/Qexp was 0.2 at the 3factor solution. However, no strong change in $\mathrm{Q} / \mathrm{Q} \exp$ was observed by further increasing the number of factors. The 4-factor solution led to the splitting of factors and no more meaningful factors could be identified

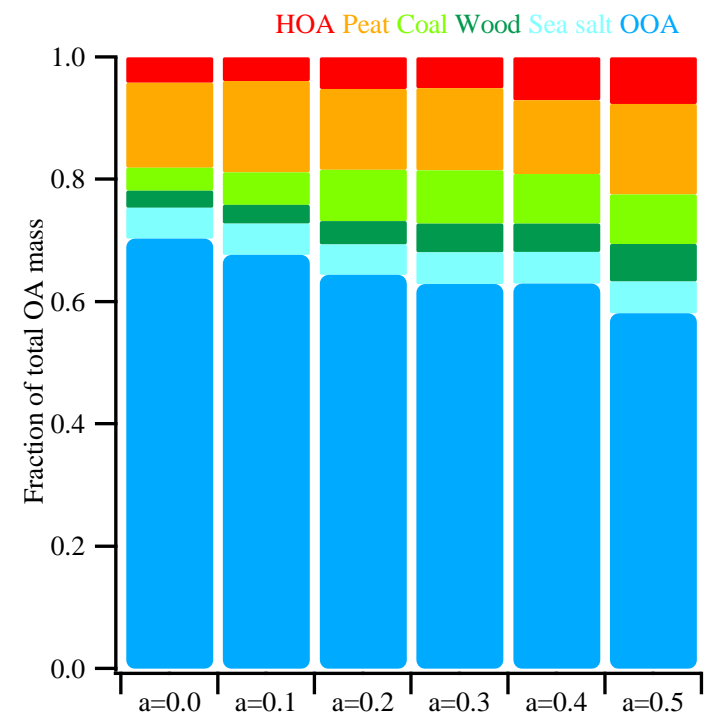

Figure S9. The relative fraction of HOA, peat, coal, wood, sea salt, and OOA factors as a function of a values. 


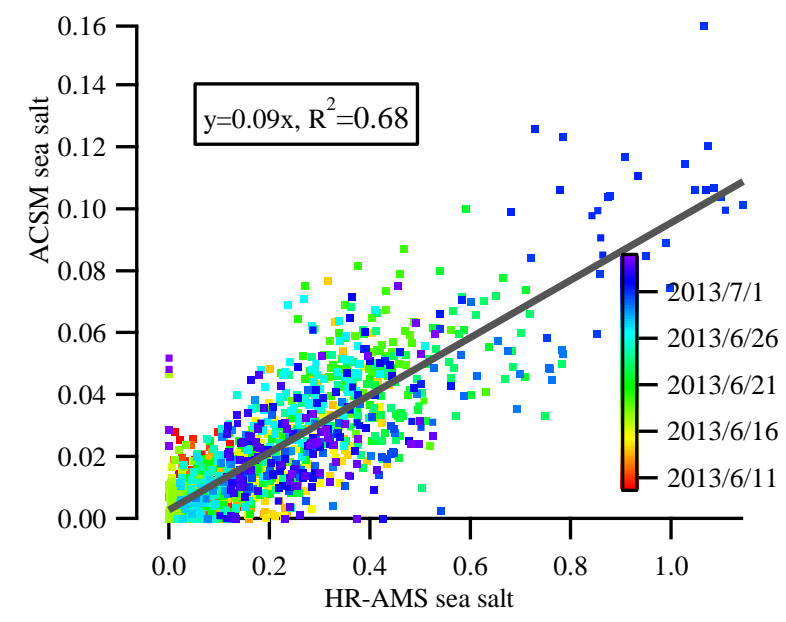

Figure S10. Comparison of the time series of sea salt between the one resolved by ACSM-PMF and the standard HR-AMS at Mace Head during summer. The slope is 0.09 . The summer data is shown here because the winter HRAMS data was not available.

(a) Mace Head

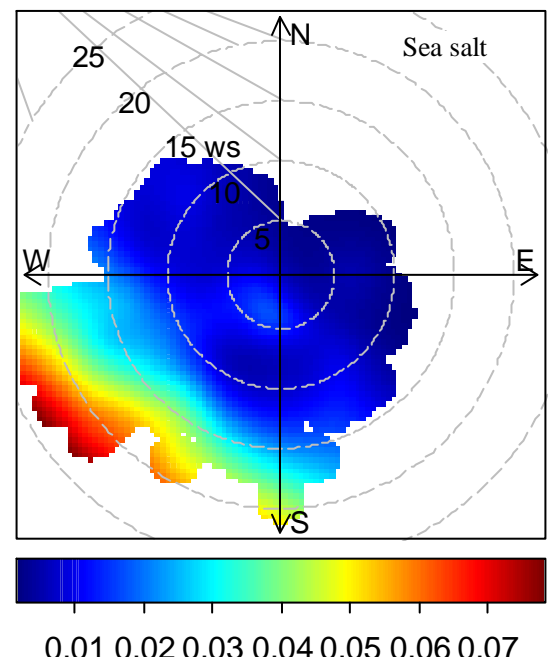

(b) Carnsore Point

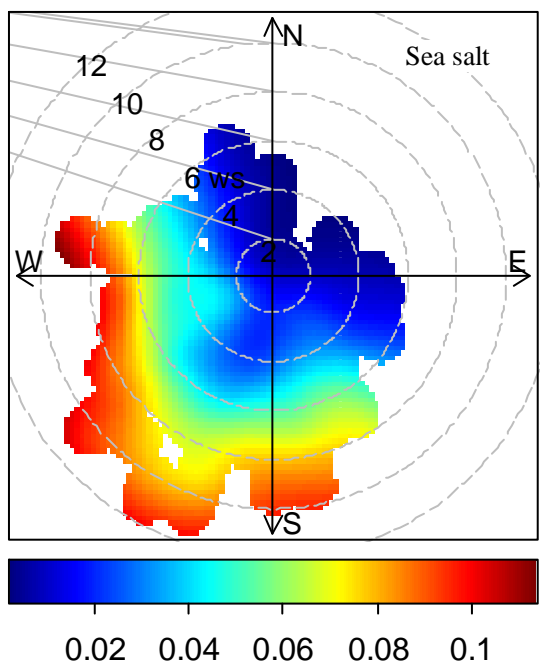

Figure S11. Wind rose of sea salt factor at Mace Head (a) and Carnsore Point (b). The plots are color-coded based on concentration of each species in $\mu \mathrm{g} \mathrm{m}^{-3}$. Wind rose plots were generated with OpenAir software in $\mathrm{R}$ (Carslaw and Ropkins, 2012). 


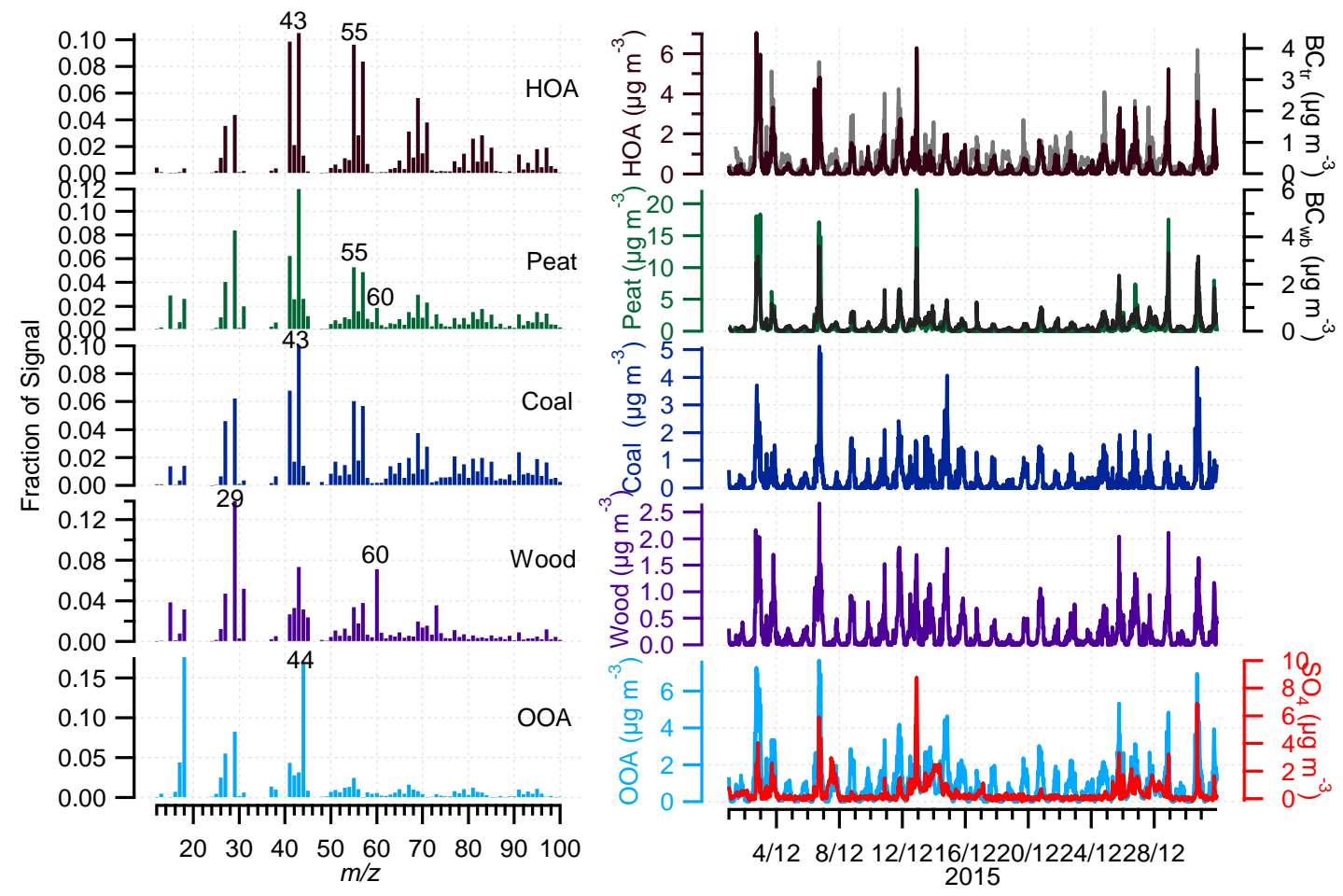

Figure S12. Profiles and time series of HOA, peat, coal, wood, and oxygenated OA (OOA) at the midland town site in Birr. The time series of $\mathrm{BC}_{\mathrm{tr}}, \mathrm{BC}_{\mathrm{wb}}$, and sulfate $\left(\mathrm{SO}_{4}\right)$ were also included to support $\mathrm{OA}$ source apportionment.
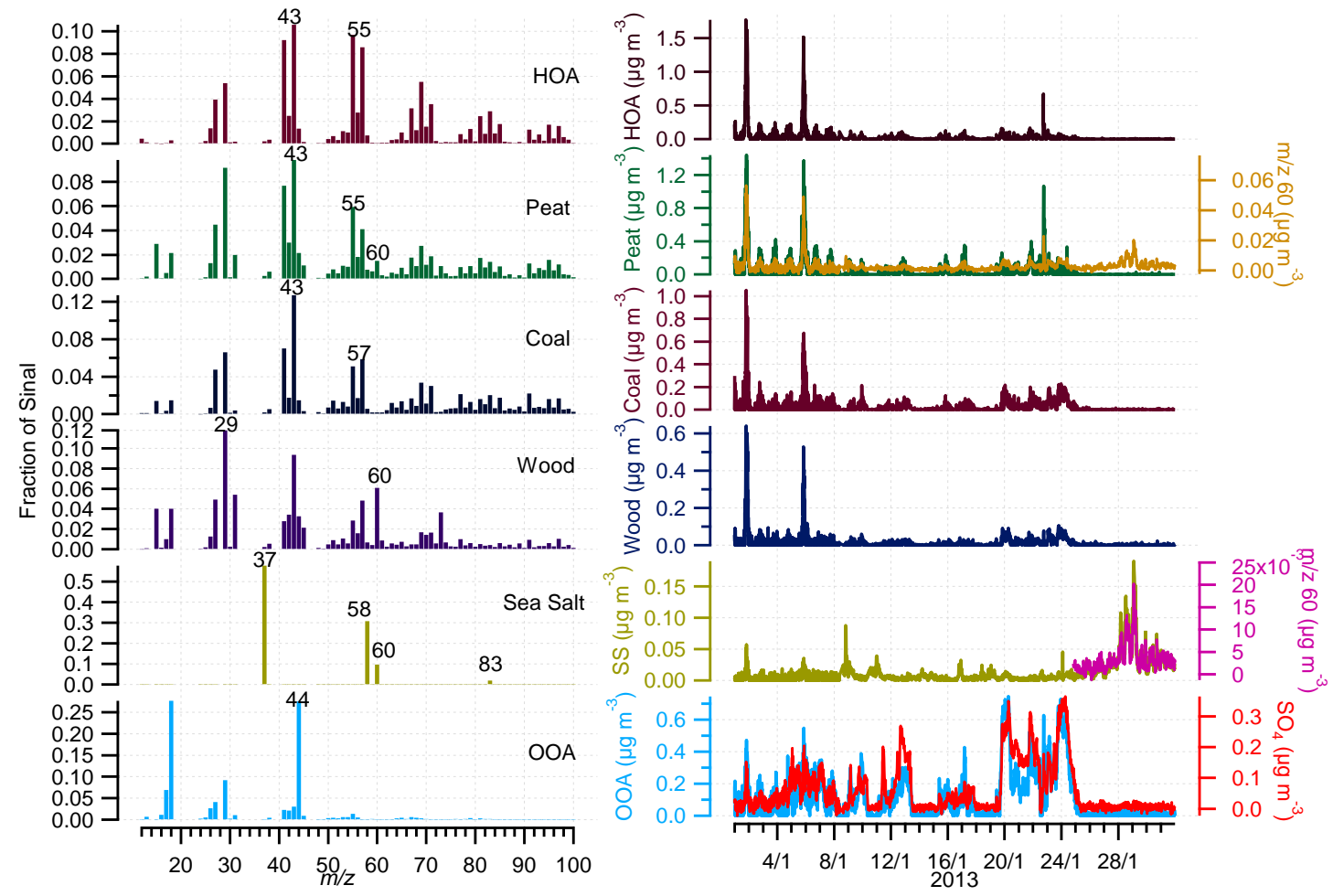

Figure S13. Profiles and time series of HOA, peat, coal, wood, sea salt, and oxygenated OA (OOA) at the coastal 
site in Mace Head. The time series of sulfate $\left(\mathrm{SO}_{4}\right)$ and $\mathrm{m} / \mathrm{z} 60$ were also included to support OA source apportionment. The time series of $\mathrm{m} / \mathrm{z} 60$ show a better correlation with sea salt than peat on 26-31 Jan.

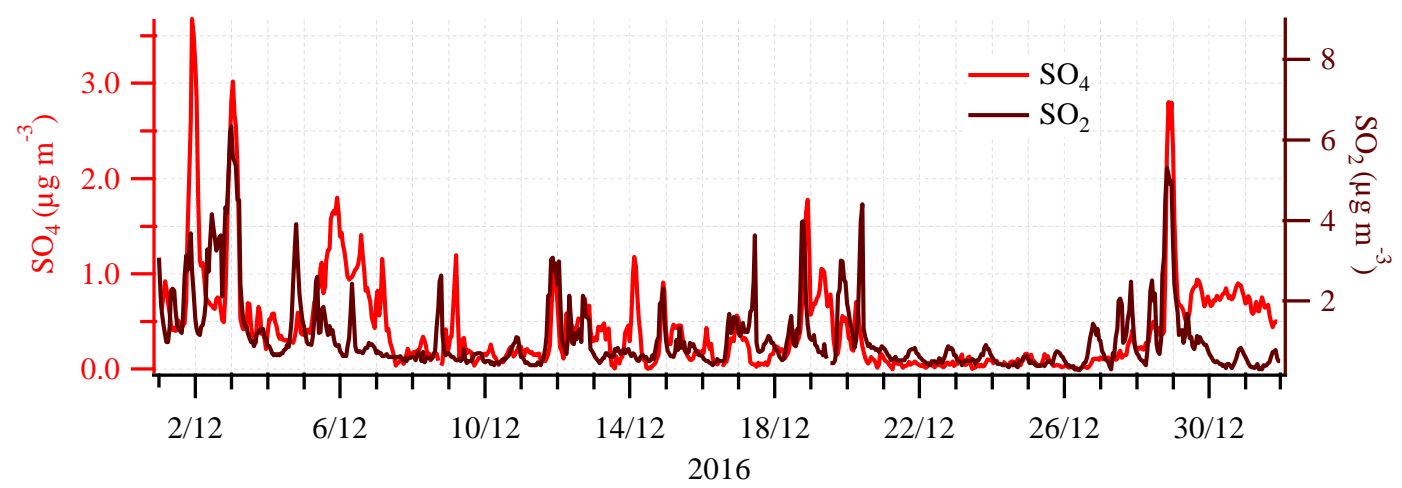

Figure S14. Time series of sulfate $\left(\mathrm{SO}_{4}\right)$ and its precursor gas of $\mathrm{SO}_{2}$ in Dublin in December 2016.

\section{References:}

Carslaw, D. C., and Ropkins, K.: Openair-an R package for air quality data analysis, Environmental Modelling \& Software, 27, 52-61, 2012. 